\title{
Veterinary herd health management programs on dairy farms in the Netherlands: Use, execution, and relations to farmer characteristics
}

\author{
M. Derks, ${ }^{* 1}$ T. van Werven, ${ }^{*}$ H. Hogeveen, ${ }^{*} \dagger$ and W. D. J. Kremer ${ }^{*}$ \\ *Department of Farm Animal Health, Faculty of Veterinary Medicine, Utrecht University, Yalelaan 7, 3584 CL Utrecht, the Netherlands \\ †Business Economics Group, Wageningen University, Hollandseweg 1, 6706 KN Wageningen, the Netherlands
}

\begin{abstract}
Veterinary herd health management (VHHM) programs are of growing importance to the dairy industry; they support farmers in the shift from curative to preventive health management, caused by increased herd sizes and quality standards in dairy farming. Farmers participating in VHHM are visited every 4 to $6 \mathrm{wk}$ by their veterinarian, who checks the animals and herd management to intervene in a proactive way with problems regarding animal health and animal welfare. At present, no good overview exists of how VHHM is executed on Dutch dairy farms, and whether different farmers require different types of VHHM. Aims of this study were to (1) map out how many farmers participate in VHHM, (2) describe how VHHM is executed on the farms, and (3) see whether certain farmer characteristics are related to farmers' participation in VHHM. In 2011, a questionnaire was sent to 5,000 Dutch dairy farmers per e-mail. Part 1 of the questionnaire focused on participation in and execution of VHHM and part 2 focused on farmer characteristics regarding external information. Returned questionnaires $(\mathrm{n}=1,013)$ were summarized and statistically analyzed. In this study $68.6 \%$ of the responding farmers participated in any form of VHHM. The most important activities were fertility checks and advice about fertility; the least important were housing and claw health. Relationships between farmer characteristics (use of and trust in information) and participation in VHHM were found.
\end{abstract}

Key words: veterinary herd health management, dairy farmer, veterinarian, farmer characteristic

\section{INTRODUCTION}

The dairy industry is evolving worldwide: industrialization and increasing competition have not only led to efficient milk production, but also to a whole new farming approach. Attention on dairy farms has shifted from the individual animal toward management on the

Received August 31, 2012.

Accepted November 24, 2012.

${ }^{1}$ Corresponding author: m.derks@uu.nl herd level (de Kruif and Opsomer, 2004; Noordhuizen and Metz, 2005; LeBlanc et al., 2006)

To cope with these changes, veterinary herd health management (VHHM) programs were set up. They are defined as a combination of (advice on) animal health, milk production, and disease prevention, placed in a framework of farm economics, welfare, food safety, and environment. Regular checks of herd and farm are important therein (Noordhuizen and Metz, 2005; LeBlanc et al., 2006). This definition is broad, but therefore meets the requirements of different dairy farming systems. Worldwide, different systems of dairy farming exist. Some are very extensive (e.g., Austria and New Zealand), whereas others are very intensive (e.g., United States). Some are seasonal (e.g., Ireland and New Zealand), whereas others are year round (e.g., Netherlands and Denmark). Some are run mostly by just 1 farmer (e.g., United Kingdom and the Netherlands) and some use workers (e.g., United States and South America). However, the topics related to (veterinary support) of dairy farming do not change between those systems. As a consequence, the amount of required VHHM skills the veterinarian should (theoretically) possess has increased from clinical medicine to an integral approach of all topics related to dairy farm management.

Not only has the veterinary work changed, but the relationship between veterinarian and farmer has changed as well. Where in the past the veterinarian was called to cure a sick cow, at present he actively approaches the farmer with advice. Farmer characteristics play an important role in the way they carry out farm management practices (Greiner et al., 2009; Ellis-Iversen et al., 2010; Kielland et al., 2010). For instance, the main goal for the farm differs substantially between farmers: whereas some focus mainly on milk production, others prefer a healthy herd, or few problems (Bergevoet et al., 2004; Kristensen and Enevoldsen, 2008). Also, the openness of dairy farmers toward external information influences their compliance to veterinary advice (Jansen et al., 2010b). So, next to technical skills, the veterinarian also should acquire people and communication skills and invest in getting to know the personality of the farmer and his goals and priorities for the farm. 
The modern veterinary practitioner thus possesses good technical skills on all topics related to dairy farming, and is able to understand farmers' drives and way of communicating. The modern dairy farmer is aware of his responsibility toward public health, animal welfare, and food safety, and is open and responsive to veterinary advice. In real life, however, that is often not the case. Farmers do not always adopt good production practices (Young, 2010) or zoonotic control programs (Ellis-Iversen et al., 2010). Veterinarians are not always aware of farmers' goals (Kristensen and Enevoldsen, 2008) and have difficulties communicating advice (Jansen et al., 2010a; Derks et al., 2012b)

It is clear that a gap exists between the ideal for VHHM and reality. At present, however, it is not clear how large the gap is, or how it should be filled. To understand what has to be done to improve VHHM on the farm, it is necessary to have a good overview of which topics are discussed with what frequency. Furthermore, because farmer characteristics appear to play a role in farm management, it is useful to determine which farmer characteristics play a role in adoption of VHHM programs on the farm. Knowing which farmers prefer which topics of VHHM makes it easier for a veterinarian to approach farmers in the right way.

This study had 3 aims: (1) to map out how many farmers participated in VHHM in the Netherlands, (2) to make an inventory of the different types and topics of VHHM that are executed on Dutch farms, and (3) to see whether certain farmer characteristics were related to farmers' participation in VHHM.

\section{MATERIALS AND METHODS}

\section{Study Design}

In September 2011, 5,000 Dutch dairy farmers with a herd size of at least 40 milking cows, participating in the monthly milk production registration (MPR), were randomly selected by CRV BV (Arnhem, the Netherlands). All farmers received a questionnaire per e-mail. Returned questionnaires were summarized and statistically analyzed.

\section{Data Collection}

Questionnaire. The questionnaire was designed using the tailored design method (Dillman, 2000) to improve lay out and response rate. It consisted of 2 distinct parts: part 1 was concerned with the architecture of VHHM on the farm and part 2 with farmer characteristics regarding external information. The questions in part 1 focused on the topics that could be discussed during VHHM (fertility checks, advice on fertility, milk production, udder health, nutrition, young stock rearing, housing, claw health, and analysis of production numbers). Because such a large variation exists in the execution of VHHM on different dairy farms, the decision whether or not they were participating in VHHM was made by the farmers. Farmers were asked whether they took part in VHHM (yes, regularly; yes, irregularly; no) and if yes, how often. Farmers who said they participate and had the veterinarian on their farm at least every $8 \mathrm{wk}$ were classified as participants.

The questions for part 2 were based on the work of Jansen et al. (2010b), who found that a relationship existed between the way farmers cope with external information and their willingness to follow veterinary advice on udder health. To enhance user friendliness and uniformity, the questions in part 2 were, where possible, constructed with a 5-point Likert scale [strongly disagree, disagree, neutral, agree, and strongly agree; Appendix Table A1, question (Q) 17-20, Q24, and Q26-30] or with yes/no (Appendix Table A1, Q12-16 and Q21-23). For Q11, multiple options were provided (courses, information nights, literature, study clubs, external advisors, internet, and other), and question 6 was open, but later stratified (<once per $2 \mathrm{yr}$, once per 2 $\mathrm{yr}$, once per year, twice per year, and $>$ twice per year).

The questionnaire was introduced to farmers by an introduction letter through the mail; the questionnaire itself was $1 \mathrm{~d}$ later sent per e-mail. The total list of questions can be found in Appendix Table A1.

Farm Data. All farmers selected for this study were participating in the monthly MPR by CRV BV. Participants in MPR receive information on milk yield, SCC, and fertility parameters of individual cows and on the herd level every 4 or 6 wk. Those variables, together with associated veterinary practice, were provided by CRV BV for each farm.

\section{Data Analysis}

General Information on the Data Set. With a Student's $t$-test, information on herd performance was compared between respondents and nonrespondents, and between participants and nonparticipants in VHHM. The normality of the data was checked visually and the difference in variance was checked with Levene's test $(P>0.05)$.

Participation in and Execution of VHHM. For each topic that could be discussed (fertility checks, advice on fertility, milk production, udder health, nutrition, young stock rearing, housing, claw health, and analysis of production numbers), 2 parameters were set: first, how many farmers discussed this topic and second, with what frequency this topic was generally discussed. 
The Relationship Between Farmer Characteristics and Participation in VHHM. A total of 20 questions from part 2 of the questionnaire, regarding farmer characteristics, were used as predictor variables in a logistic regression model. Outcome variable was participation in VHHM (yes/no). First, all variables were tested in a univariate model (Appendix Table A2). Significant predictor variables $(P<0.20)$ were used in a multivariable model. Variable selection was done using a backward regression. The veterinary practice the farmer was associated with was included in the model as a covariate.

The goodness-of-fit of the data was checked using the Hosmer-Lemeshow test. Multicollinearity was checked with tolerance and variance inflation factor statistics. The crude model was adjusted 3 times by adding a different covariate (first: number of cows; second: veterinary practice size; third: number of cows $\times$ veterinary practice size) through forced entry. The models were compared using the Hosmer-Lemeshow test, Nagelkerke's coefficient of determination, and difference in chi-squared. The final model could be described as follows:

$$
\begin{aligned}
& \mathrm{VHHM}= \\
& \left(\frac{e \beta 0+\beta 1 \times Q 2+\beta 2 \times Q 3+\beta 3 \times Q 5+\beta 4 \times Q 8+\beta 5 \times Q 13+\beta 6 \times Q 15+\beta 7 \times Q 17+\beta 8 \times A V P}{1+e \beta 0+\beta 1 \times Q 2+\beta 2 \times Q 3+\beta 3 \times Q 5+\beta 4 \times Q 8+\beta 5 \times Q 13+\beta 6 \times Q 15+\beta 7 \times Q 17+\beta 8 \times A V P}\right),
\end{aligned}
$$

where VHHM represents participation in VHHM yes/no, $\beta 0$ represents the estimated intercept, and the regression coefficients $\beta(1-8)$ were estimated for the relevant questions $Q(\mathrm{x})$ and associated veterinary practice $(A V P)$.

The Relationship Between Farmer Characteristics and Level of Participation in VHHM. The 20 questions from part 2 of the questionnaire were used as predictor variables in an ordinal logistic regression model. The number of regularly discussed topics $($ minimum $=0$; maximum $=9)$ was used as the outcome variable. First, all variables were tested in a univariate model. For the complete model, all variables that were significant $(P<$ 0.20) in the univariate model were put in using backward regression (Appendix Table A3). Associated veterinary practice was included in the model as a covariate.

The crude model was adjusted in the same way as the logistic regression model. The models were compared using Nagelkerke's coefficient of determination and the difference in Pearson chi-squared. The final model could be described as follows:

$$
\begin{aligned}
& \text { NoT }= \\
& \left(\frac{e \beta 0+\beta 1 \times Q 5+\beta 2 \times Q 6+\beta 3 \times Q 8+\beta 4 \times Q 13+\beta 5 \times Q 15+\beta 6 \times N C \times V P S+\beta 7+A V P}{1+e \beta 0+\beta 1 \times Q 5+\beta 2 \times Q 6+\beta 3 \times Q 8+\beta 4 \times Q 13+\beta 5 \times Q 15+\beta 6 \times N C \times V P S+\beta 7 \times A V P}\right),
\end{aligned}
$$

where NoT represents number of discussed topics, $\beta 0$ represents the estimated intercept, and the regression coefficients $\beta(1-7)$ were estimated for the relevant questions $Q(\mathrm{x})$, number of cows $\times$ veterinary practice size $(N C \times$ $V P S)$ and associated veterinary practice $(A V P)$.

\section{RESULTS}

\section{General Information on the Data Set}

Five thousand famers, associated with 270 veterinary practices, were approached to join the study, of which 1,013 returned the questionnaire (20\%). No significant difference was observed in the response rate between practices. Nonrespondents had more cows, a higher SCC, a longer calving interval, and fewer kilograms of milk per cow per year than respondents. Participants in VHHM had a higher milk production and a lower SCC than nonparticipants (Table 1).

\section{Participation in and Execution of VHHM}

Of the respondents, 695 participated in VHHM (68.6\%) and 318 did not. Eighty-five percent of the farmers had their cows checked for pregnancy regularly (Figure 1). Advice concerning fertility took place on $70.9 \%$ of the participating farms on a regular basis. Most farmers (65.2\%) discussed production numbers with their veterinarian on a regular basis and 19\% never discussed them. Topics that were discussed least often on a regular basis were claw health (31\%) and housing (25.1\%). The use or number of discussed topics did not significantly differ between veterinary practices. No correlation between farm size and number of discussed topics was found. 


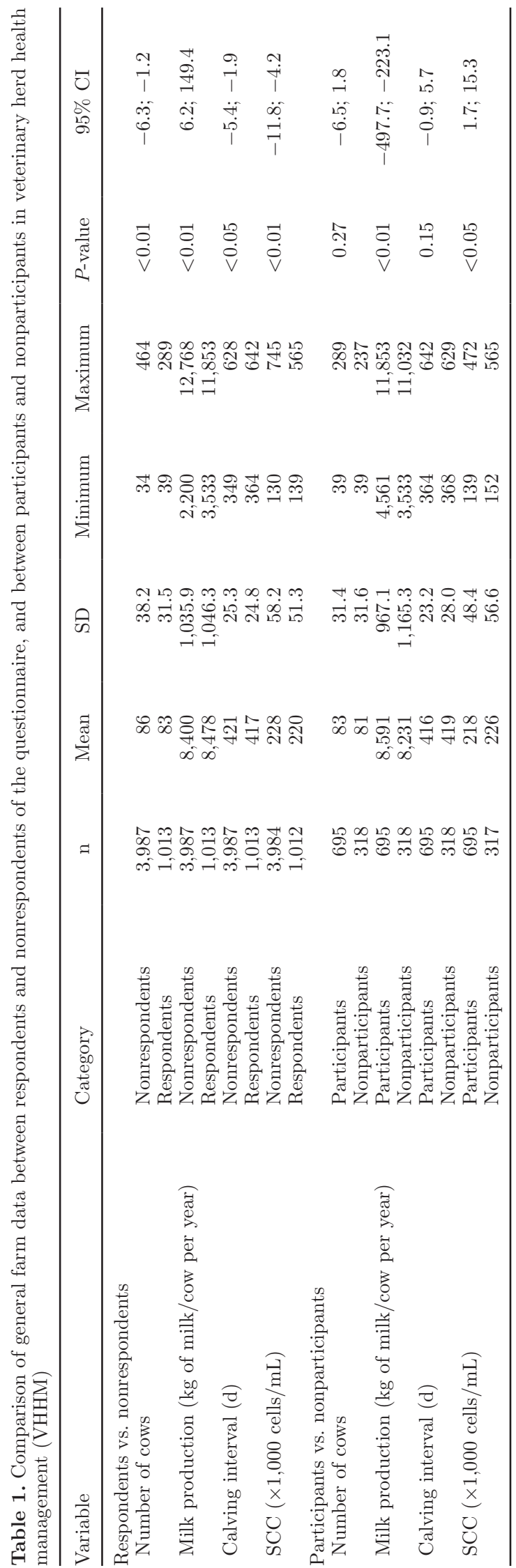

Looking at the combinations of topics regularly discussed during VHHM, the most common form of VHHM was the one in which all topics were discussed (Table 2). Pregnancy checks were performed in all of the most common combinations, followed by advice on fertility, analysis of production numbers, milk production, and udder health. A remarkable finding was that if one of the previously named topics was not discussed, the remaining topics (nutrition, young stock rearing, claw health, and housing) also were not discussed.

\section{Farmer Characteristics Regarding External Information}

The farmers in this study acquired information from several sources (Table 3), of which external advisors $(26.6 \%)$ and the literature $(25.3 \%)$ were the most important. Eighty-two percent of the farmers actively visited farms outside their region to gain new knowledge. About two-thirds of the farmers (66.9\%) would consider becoming a testing farm for a new product or service; $28 \%$ had already been a testing farm in the past.

Farmers said they were compliant with external advice (Table 3). Veterinary advice was followed up more often $(83.2 \%)$ than advice from the feed advisor (78\%). Most farmers were willing to discuss new topics when their veterinarian asked them to $(83.4 \%)$. The professional relationship between farmer and veterinarian can be classified as good: only $4.3 \%$ of the veterinarians received a grade below 6 on a scale from 1 to 10, and $60.5 \%$ received an 8 or higher. Although the veterinarian is appreciated by the farmer and veterinary advice is followed up quite well, most farmers also indicated that external advice in general did not add up to their own knowledge (55\%). Costs were an important reason not to use external advisors $(43.2 \%)$.

In terms of trust, most farmers appeared to trust their veterinarian and other farmers. Almost all farmers allowed their veterinarian to see their farm data $(96.2 \%)$, and $59.9 \%$ did not mind sharing their farm data with other farmers. Other farmers were not seen as competition (93.8\%).

\section{The Relationship Between Farmer Characteristics and Participation in VHHM}

After comparing the different multivariate models, the crude model, with no forced entries, fitted the data best; both the Hosmer-Lemeshow test and the chisquared were highest. The number of cows, veterinary practice size, and the interaction between them were not significant predictors in the model. Farmers that participated in study clubs, tried to improve their farm management, or were open to test new products or ser- 
Table 2. Overview of the most common combinations of topics discussed during veterinary herd health management (VHHM), filled out by farmers

\begin{tabular}{|c|c|c|c|c|c|c|c|c|c|}
\hline $\mathrm{n}$ & $\begin{array}{c}\text { Pregnancy } \\
\text { checks }\end{array}$ & $\begin{array}{c}\text { Advice } \\
\text { on fertility }\end{array}$ & $\begin{array}{c}\text { Advice on } \\
\text { production } \\
\text { numbers }\end{array}$ & $\begin{array}{l}\text { Udder } \\
\text { health }\end{array}$ & $\begin{array}{c}\text { Milk } \\
\text { production }\end{array}$ & Nutrition & $\begin{array}{l}\text { Young } \\
\text { stock } \\
\text { rearing }\end{array}$ & $\begin{array}{c}\text { Claw } \\
\text { health }\end{array}$ & Housing \\
\hline 60 & $\mathrm{x}$ & $\mathrm{x}$ & $\mathrm{x}$ & $\mathrm{x}$ & $\mathrm{x}$ & $\mathrm{x}$ & $\mathrm{x}$ & $\mathrm{x}$ & $\mathrm{x}$ \\
\hline 40 & $\mathrm{x}$ & $\mathrm{x}$ & $\mathrm{x}$ & $\mathrm{x}$ & $\mathrm{x}$ & $\mathrm{x}$ & & & \\
\hline 33 & $\mathrm{x}$ & & & & & & & & \\
\hline 29 & $\mathrm{x}$ & $\mathrm{x}$ & & & & & & & \\
\hline 18 & $\mathrm{x}$ & $\mathrm{x}$ & $\mathrm{x}$ & $\mathrm{x}$ & $\mathrm{x}$ & $\mathrm{x}$ & $\mathrm{x}$ & $\mathrm{x}$ & \\
\hline 18 & $\mathrm{x}$ & $\mathrm{x}$ & $\mathrm{x}$ & $\mathrm{x}$ & $\mathrm{x}$ & $\mathrm{x}$ & $\mathrm{x}$ & & $\mathrm{x}$ \\
\hline 15 & $\mathrm{x}$ & $\mathrm{x}$ & $\mathrm{x}$ & $\mathrm{x}$ & $\mathrm{x}$ & & & & \\
\hline 15 & $\mathrm{x}$ & $\mathrm{x}$ & $\mathrm{x}$ & $\mathrm{x}$ & $\mathrm{x}$ & $\mathrm{x}$ & $\mathrm{x}$ & & \\
\hline 14 & $\mathrm{x}$ & $\mathrm{x}$ & $\mathrm{x}$ & $\mathrm{x}$ & $\mathrm{x}$ & $\mathrm{x}$ & & $\mathrm{x}$ & \\
\hline 12 & $\mathrm{x}$ & $\mathrm{x}$ & $\mathrm{x}$ & & & & & & \\
\hline 11 & $\mathrm{x}$ & $\mathrm{x}$ & $\mathrm{x}$ & $\mathrm{x}$ & & & & & \\
\hline 10 & $\mathrm{x}$ & $\mathrm{x}$ & $\mathrm{x}$ & $\mathrm{x}$ & $\mathrm{x}$ & & $\mathrm{x}$ & & \\
\hline
\end{tabular}

vices, were more likely to participate in VHHM (Table 4). Also, a good relationship with the veterinarian and compliance with veterinary advice had positive effects on participation in VHHM. However, farmers participating in a board or committee regarding dairy farming were found to be less likely to participate in VHHM.

\section{The Relationship Between Farmer Characteristics and Level of Participation in VHHM}

The model with forced entry of number of cows $x$ veterinary practice size fitted the data best, based on values for Pearson chi-squared and Nagelkerke's coef- ficient of determination (Table 5). Farmers that had good relationships with their veterinarian had a higher probability of discussing more topics during VHHM. The same was true for farmers who invested in farm management, who were willing to share farm data, or who were open to being a testing farm in the future.

\section{DISCUSSION}

This study is the first large-scale study on the present performance of VHHM in the Netherlands and farmer characteristics related to VHHM. Judging from the fit of the logistic and ordinal logistic regression models

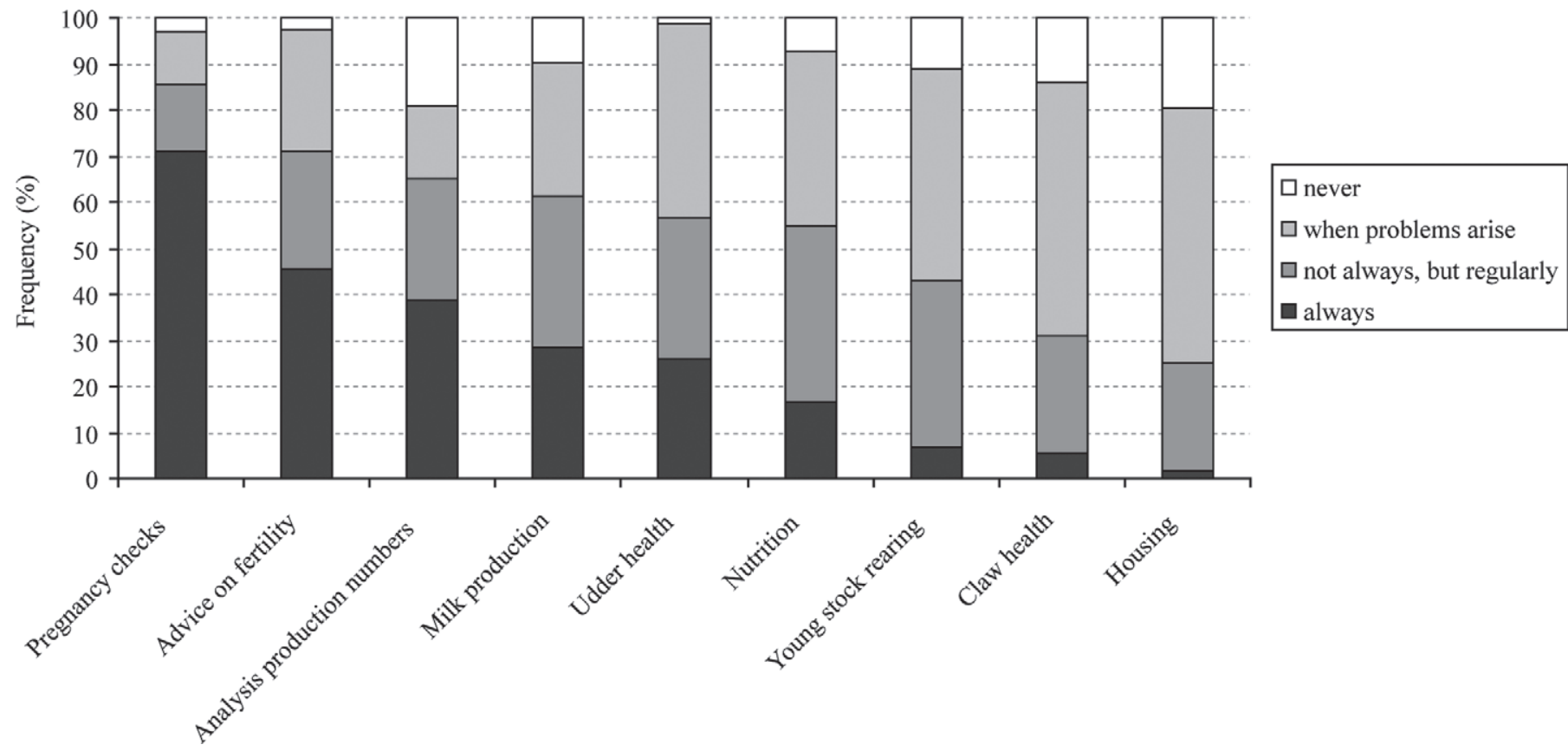

Figure 1. Overview of the frequency with which 9 veterinary herd health management (VHHM) topics are discussed during farm visits (n $=627)$. 
Table 3. Frequency distribution of the answers of 1,013 farmers to the 20 questions regarding external information (\%)

\begin{tabular}{|c|c|c|c|c|c|c|c|c|}
\hline Question & Agree & Disagree & & & & & & \\
\hline I take part in a study club & 57.2 & 42.8 & & & & & & \\
\hline I take part in a committee/board regarding (dairy) farming & 22.2 & 77.8 & & & & & & \\
\hline I receive visitors on my farm & 51.5 & 48.5 & & & & & & \\
\hline I view other farmers as competition & 93.8 & 6.2 & & & & & & \\
\hline I have been a testing farm for a new product/service & 28.0 & 72.0 & & & & & & \\
\hline If I were approached to be a testing farm, I would consider it & 66.9 & 33.1 & & & & & & \\
\hline \multirow[t]{2}{*}{ My veterinarian may see my farm data } & 96.2 & 3.8 & & & & & & \\
\hline & Agree & Neutral & Disagree & & & & & \\
\hline I allow others to visit my farm & 18.6 & 30.7 & 50.7 & & & & & \\
\hline I follow the advice of my feed advisor & 78.0 & 20.5 & 1.5 & & & & & \\
\hline I follow the advice of my veterinarian & 83.2 & 15.3 & 1.5 & & & & & \\
\hline External advice does not add to my own knowledge & 55.0 & 32.2 & 12.8 & & & & & \\
\hline The most important reason not to use external advisors is a financial reason & 43.2 & 28.6 & 28.1 & & & & & \\
\hline I like to be the first to use new developments & 20.8 & 53.1 & 26.1 & & & & & \\
\hline I continuously try to improve farm management & 71.3 & 23.4 & 5.3 & & & & & \\
\hline If I hear about interesting developments in dairy, I look it up on the internet & 41.6 & 35.3 & 23.1 & & & & & \\
\hline If my veterinarian wants to talk about a new topic, I am open to that & 83.4 & 14.8 & 1.8 & & & & & \\
\hline \multirow[t]{2}{*}{ I do not like to share my farm data with other farmers } & 13.9 & 26.2 & 59.9 & & & & & \\
\hline & Never & Once/2 yr & $\begin{array}{l}\text { Once per } \\
\text { year }\end{array}$ & $\begin{array}{l}\text { Twice per } \\
\text { year }\end{array}$ & $\begin{array}{l}>\text { Twice per } \\
\text { year }\end{array}$ & & & \\
\hline \multirow{2}{*}{$\begin{array}{l}\text { How often do you visit other farms outside your region }(>50 \mathrm{~km}) \\
\text { to gain new knowledge? }\end{array}$} & 18.0 & 17.1 & 28.2 & 19.1 & 17.7 & & & \\
\hline & Courses & $\begin{array}{l}\text { Information } \\
\text { nights }\end{array}$ & Literature & Study club & Advisor & Internet & Other & \\
\hline \multirow[t]{3}{*}{ Where do you get information on animal health? } & 8.6 & 14.2 & 25.3 & 12.8 & 26.6 & 12.0 & 0.5 & \\
\hline & & & & Scale & & & & \\
\hline & 3 & 4 & 5 & 6 & 7 & 8 & 9 & 10 \\
\hline I grade the relationship with my veterinarian a . . (1-10) & 0.9 & 0.8 & 2.6 & 7.4 & 27.8 & 43.9 & 13.0 & 3.6 \\
\hline
\end{tabular}

the relationship with my veterinarian a . . . (1-10) 
Table 4. Outcomes of a logistic regression analysis with dependent variable [participation in veterinary herd health management (VHHM; yes/ no)] and independent variables [the 20 questions (Q) regarding the use of information] ${ }^{1}$

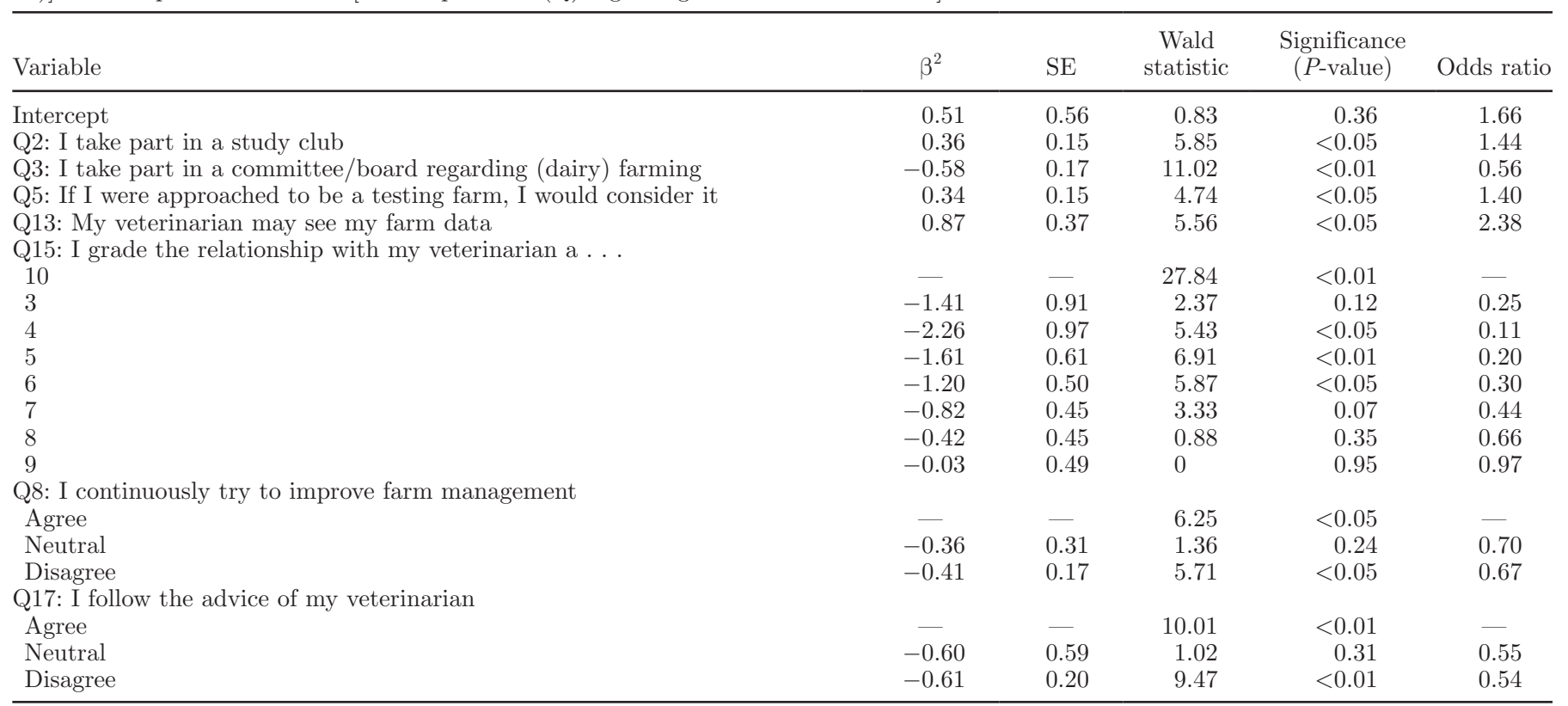

${ }^{1}$ Information for goodness-of-fit: Hosmer-Lemeshow: $P=0.92$; Nagelkerke's $\mathrm{R}^{2}=0.14$; tolerance statistics: $>0.1$, variance inflation factor statistics: $<10$.

${ }^{2}$ The regression coefficient, representing the relative importance of a predictor in predicting the criterion.

Table 5. Outcomes of an ordinal logistic regression analysis with dependent variable [number of topics discussed during veterinary herd health management (VHHM; 1-9)] and independent variables [the 20 questions (Q) regarding the use of information and forced entry of "number of cows $\times$ veterinary practice size"] $]^{1}$

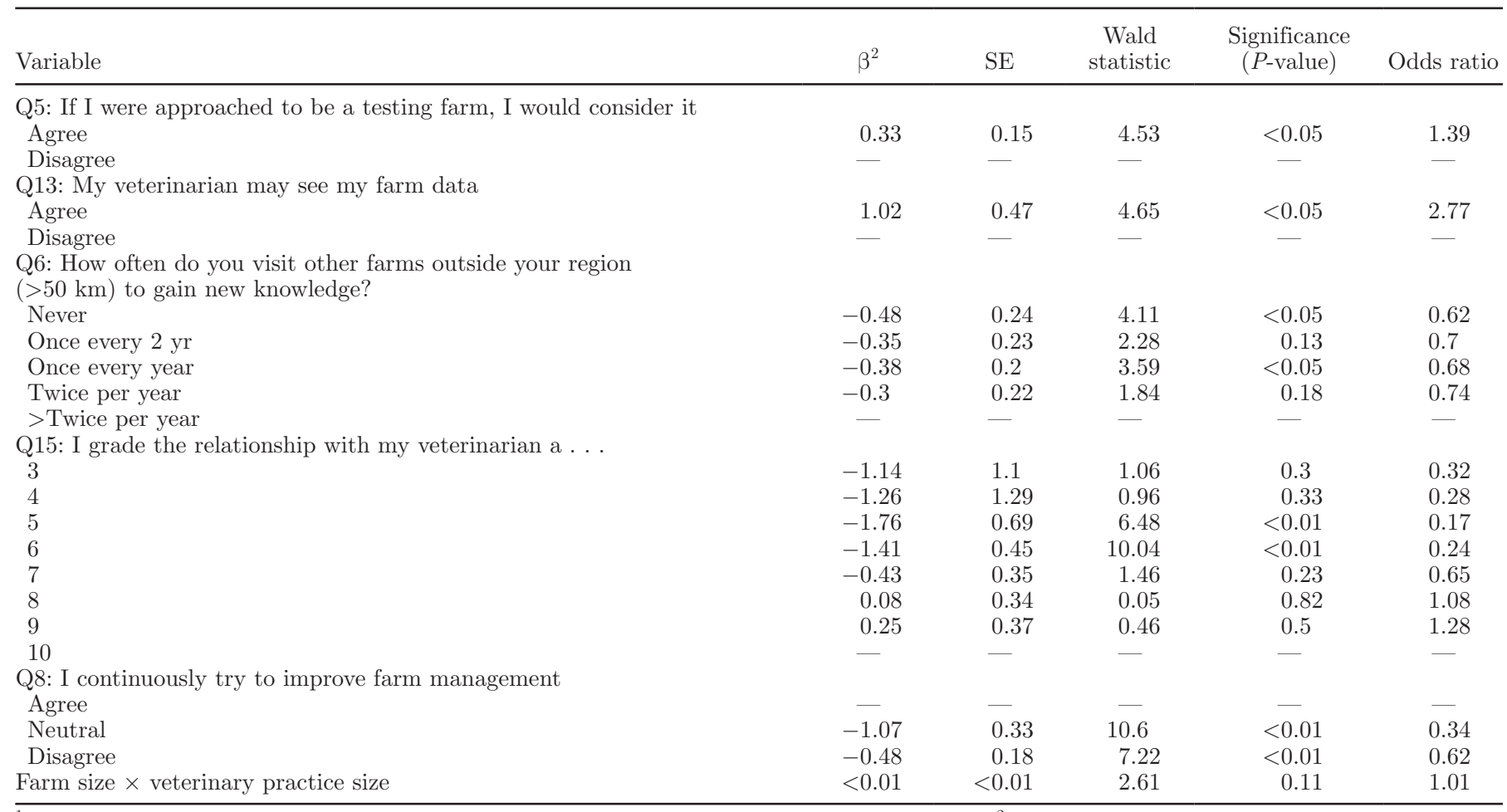

${ }^{1}$ Information for goodness-of-fit: Pearson chi-squared goodness-of-fit: $P=0.77$; Nagelkerke's $\mathrm{R}^{2}=0.113$.

${ }^{2}$ The regression coefficient, representing the relative importance of a predictor in predicting the criterion. 
$\left(\mathrm{R}^{2}=0.140\right.$ and 0.113 , respectively), farmers' characteristics regarding information do explain part of the variance in participation in VHHM, but not all. One important influence that may have been left out of the picture was (the social and practical skills of) the veterinarian. There are as many different veterinarians as there are different farmers; one may be a good technician, another a good communicator, and a third may be both. Whether or not a farmer starts participating in VHHM may very well depend on how well the veterinarian explains the benefits. Discussion of topics such as, for instance, housing may depend on the veterinarians' knowledge on that topic. Results of a study on Johne's disease control programs show that the level of compliance of farmers is dependent on the quality of the veterinary advice (Sorge et al., 2010).

For this study, it was not possible to examine the specific and unique relationship between veterinarian and farmer, as measuring the strength of this relationship goes beyond one questionnaire. More in-depth qualitative analyses are needed (interviews and recordings of VHHM conversations) to create a golden standard for a well-executed VHHM visit. Asking farmers alone how they perceive their veterinarian is not enough; the work of Jansen et al. (2010a) shows that farmers can be very satisfied with their veterinarian even if communication skills are under par (Jansen et al., 2010a). More research on the effect of this relationship on participation in VHHM is, therefore, needed and the authors recommend viewing the described results in the light of the possible bias created by that relationship.

In the introduction, it was already stated that, although the overall definition of VHHM can be used for dairy farms worldwide, the way dairy farms operate can differ quite a lot between countries. The results of this study are particularly interesting for dairy farming systems that resemble the Dutch situation: mostly family farms of about 80 cows, milking in a year-round system. However, the authors do believe that especially the results of aim 3 (farmer characteristics related to participation) can be extrapolated to other types of dairy farming. Previous studies in the United Kingdom (Hall and Wapenaar, 2012), Canada (Sorge et al., 2010), and New Zealand (Brownlie et al., 2011) have shown that farmers' attitudes play a big role in compliance to herd health programs there as well.

\section{General Information on the Data Set}

From the 5,000 questionnaires that were sent out, 1,013 were returned fully completed $(20 \%)$ and, therefore, $80 \%$ of our selected population did not respond. Farmers who did not respond to the survey generally had more cows, lower milk production per cow per year, a longer calving interval and a higher SCC (Table 1). The differences, however, were small, and the effect of response bias is, therefore, expected to be limited.

Several measures were taken upfront to prevent survey bias: farmers were selected randomly, and the questionnaire was designed using the tailored design method by Dillman (2000). This is a validated method to improve response rate of questionnaires (Dillman, 2000). However, the response rate for this questionnaire was quite low compared with other studies (Lievaart and Noordhuizen, 1999; Bergevoet et al., 2004). One reason for the low response rate may be that we surveyed the farmers in September. In previous research, farmers indicated that the summer months were not good months to receive a survey (Pennings et al., 2002). Second reason for the low response rate may be that the questionnaires were sent by CRV for anonymity reasons. Most dairy farmers receive a lot of information by CRV. The questionnaire may, therefore, have been overlooked or not even opened.

\section{Participation in and Execution of VHHM}

Based on the oral information of approximately 20 veterinary practices, the average veterinary practice had about 25 to $50 \%$ of its farmers enrolled in VHHM. The percentage of respondents participating in VHHM in this study was, therefore, quite high (68.6\%). This may have been caused by response bias: people who are interested in the survey topic tend to respond more easily (Huang et al., 2003; Dillman, 2000). In the results of this survey, VHHM enthusiasts may, therefore, be overrepresented in comparison with the general population of Dutch dairy farmers. No scientific literature exists, however, on the number of farmers participating in VHHM in the Netherlands to compare with our results.

The most common combinations of discussed topics showed a specific pattern of VHHM (Table 2). Farmers that discuss nutrition, claw health, young stock, or housing, are very likely to also discuss milk production, udder health, production numbers, and fertility with their veterinarian. It thus appears as if a distinction exists between primary and secondary topics. Based on literature on animal health economics, it is worth discussing whether some secondary topics, such as claw health and young stock rearing, deserve more attention. On a dairy farm, the difference in net losses due to fertility between good and average farms are up to $€ 34$ per cow per year (Inchaisri et al., 2010). The net losses due to foot disorders on an average dairy farm are $€ 75$ per cow per year (Bruijnis et al., 2010). Rearing costs of young stock account for $13 \%$ of the total cost price for milk (Mohd Nor et al., 2012), which equals €509.84 per cow per year. Fertility is, thus, not the highest expendi- 
ture. Therefore, the authors argue that claw health and young stock are the topics to be discussed in the future, and urge both veterinarians and farmers to pay more attention to those topics.

\section{Farmer Characteristics Regarding External Information}

The second part of the questionnaire was based on the work of Jansen et al. (2010b) on hard-to-reach farmers (Jansen et al., 2010b). The first intention was to divide them into the 4 groups (do-it-yourselfers, proactivists, reclusive traditionalists, and wait-andseers), as described by Jansen et al. (2010b). After validation studies with factor analysis and Cronbach's $\alpha$, the model did not fit the data. The factor analysis produced 5 factors in which both questions regarding the openness toward external information and those regarding trust in external information were mixed (results in Appendix, Tables A4 and A5). Both sets of questions (openness toward information and trust in information) have also been tested with a Cronbach's $\alpha$ separately. Both did not meet the threshold of 0.70 set upfront (openness toward information: 0.66; trust in information: 0.47 ) and were, therefore, not combined for further analysis.

Several explanations exist as to why the model of Jansen et al. (2010b) did not fit our data. First, the farmers in the study by Jansen et al. (2010b) were qualified as being hard to reach by their veterinarian. Therefore, it was not expected that the veterinarian had a lot of influence on the farms. In our study, almost $67 \%$ of the farmers were enrolled in some form of VHHM. The veterinarian may be a more important sparring partner in our population. A second explanation could be that our questionnaire was not valid for this model. To improve response rate, the questionnaire was kept as short as possible. Therefore, some aspects of information use, a broad topic, may very well not have been covered.

Farmers indicated that external advisors were their most important source of information. They also indicated that advice from veterinarians and food advisors were followed up on and that the relationship with their veterinarian was good. Still, over half of the farmers said that external advice did not add to their own knowledge. These results raise the question whether gaining external information is the main reason for farmers to participate in VHHM. Maybe other factors, such as farm support and prevention of organizational blindness, play a role in a farmers' decision whether or not to participate in VHHM. These factors have been proven important to participants in VHHM (Lievaart and Noordhuizen, 1999; Derks et al., 2012a,b). It is worth exploring the reasons why farmers pay for veterinary advice, as it might affect the way the farmer needs to be approached. Knowing what drove the farmer to participate in VHHM may facilitate the veterinarians' choice to support decisions, be a fresh pair of eyes, or provide new developments or prevention strategies.

\section{The Relationship Between Farmer Characteristics and Participation in VHHM}

The relationship with the veterinarian was a significant predictor for participation in VHHM in the model. To be seen by the farmer as a trustworthy advisor, the veterinarian needs to build up a trustworthy relationship (Maister et al., 2000). Because VHHM is based on preventive advice, the strength of the relationship is an important contributor to the success of VHHM. Participation in VHHM was higher in farmers that took part in study clubs, who were continuously improving farm management and who were willing to participate in a testing program. These results indicate that farmers who were proactive and curious for new developments and information had a higher probability of joining VHHM. However, if farmers were active in a board or committee regarding dairy farming, they were less likely to participate in VHHM, which does not fit the previous hypothesis. Possibly an optimum exists for openness toward external information, at least in our surveyed population. However, no literature exists on farmers' attitudes in relation to the level of participation in preventive veterinary advice to support or oppose our findings.

\section{The Relationship Between Farmer Characteristics and Level of Participation in VHHM}

From the ordinal multivariable logistic regression model, it was shown that for the amount of topics discussed, the relationship with the veterinarian was a significant predictor. Also, farmers that were open to being a testing farm and who were continuously trying to improve farm management were more likely to discuss a greater amount of topics. The same reasoning as with participation in VHHM can be applied here. If farmers are more open to new developments and information, they are more interested in talking about different topics. Farmers who allowed their veterinarian to see their farm data were more likely to discuss more topics. This was as expected, as to discuss topics such milk production, udder health, and fertility management in depth, it is important for the veterinarian to have access to the farm's management data (LeBlanc et al., 2006). 
Although much research has been conducted on the attitudes of farmers toward preventive measures, the link between those attitudes and the amount of advice farmers purchase from their veterinarian has not been made before. When more studies on the relationship between (veterinary) advice, personal communication, and farmers' attitudes are conducted in the future, veterinarians can start to differentiate between their farmers, and provide tailor-made VHHM. This is both good for efficiency and effectiveness.

\section{CONCLUSIONS}

In this study, approximately two-thirds of the responding dairy farmers received some form of VHHM. Topics that were often discussed were fertility, milk production, and udder health. Topics that were discussed less often were claw health, young stock, and housing, even though economic benefits of improving these topics may be substantial. Personal characteristics of the farmer were related to the use of and participation in VHHM. More research on these relationships may support the veterinarian in marketing VHHM to dairy farmers.

\section{ACKNOWLEDGMENTS}

The authors kindly acknowledge all farmers. Also, we thank Stephan Ramaekers of the Faculty of Social Sciences, Centre of Education and Learning Utrecht University (COLUU, Utrecht, the Netherlands), for his help with the analysis of the questionnaire and Hans Vernooij of the Faculty of Veterinary Medicine, Department of Farm Animal Health, Utrecht University, for his great input for the statistical analyses. Last, but not least, we thank CRV BV (Arnhem, the Netherlands) for providing the data and funding this study.

\section{REFERENCES}

Bergevoet, R. H. M., C. J. M. Ondersteijn, H. W. Saatkamp, C. M J. van Woerkum, and R. B. M. Huirne. 2004. Entrepreneurial behaviour of Dutch dairy farmers under a milk quota system: Goals, objectives and attitudes. Agric. Syst. 80:1-21.

Brownlie, T. S., A. M. Weir, I. Tarbotton, J. M. Morton, C. Heuer, and S. McDougall. 2011. Reproductive management of dairy herds in New Zealand: Attitudes, priorities and constraints perceived by farmers managing seasonal-calving, pasture-based herds in four regions. N. Z. Vet. J. 59:28-39.

Bruijnis, M. R. N., H. Hogeveen, and E. N. Stassen. 2010. Assessing economic consequences of foot disorders in dairy cattle using a dynamic stochastic simulation model. J. Dairy Sci. 93:2419-2432.

de Kruif, A., and G. Opsomer. 2004. Integrated dairy herd health management as the basis for prevention. Vlaams Tijdschr. Diergeneeskd. 73:44-52.
Derks, M., L. M. A. van de Ven, T. van Werven, W. D. J. Kremer, and H. Hogeveen. 2012a. The perception of veterinary herd health management by Dutch dairy farmers and its current status in the Netherlands: A survey. Prev. Vet. Med. 104:207-215.

Derks, M., T. van Werven, H. Hogeveen, and W. D. J. Kremer. 2012b. Straightening out priorities: How aware is the veterinarian of farmers' wishes and goals regarding veterinary herd health management? Abstract Book XXVII World Buiatrics Congress 2012. OC:221: 23 .

Dillman, D. A. 2000. Mail and Internet Surveys: The Tailored Design Method. John Wiley \& Sons, New York, NY.

Ellis-Iversen, J., A. J. C. Cook, E. Watson, M. Nielen, L. Larkin, M. Wooldridge, and H. Hogeveen. 2010. Perceptions, circumstances and motivators that influence implementation of zoonotic control programs on cattle farms. Prev. Vet. Med. 93:276-285.

Greiner, R., L. Patterson, and O. Miller. 2009. Motivations, risk perceptions and adoption of conservation practices by farmers. Agric. Syst. 99:86-104.

Hall, J., and W. Wapenaar. 2012. Opinions and practices of veterinarians and dairy farmers towards herd health management in the UK. Vet. Rec. 170:441.

Huang, J. Y., S. M. Hubbard, and K. P. Mulvey. 2003. Obtaining valid response rates: Considerations beyond the tailored design method. Eval. Program Plann. 26:91-97.

Inchaisri, C., R. Jorritsma, P. L. A. M. Vos, G. C. van der Weijden, and H. Hogeveen. 2010. Economic consequences of reproductive performance in dairy cattle. Theriogenology 74:835-846.

Jansen, J., R. J. Renes, H. Klinkert, and T. J. G. M. Lam. 2010a. Improving Udder Health Management: Veterinarians' Perceptions and Communication Skills. Wageningen University, Wageningen, the Netherlands.

Jansen, J., C. D. M. Steuten, R. J. Renes, N. Aarts, and T. J. G. M. Lam. 2010b. Debunking the myth of the hard-to-reach farmer: Effective communication on udder health. J. Dairy Sci. 93:12961306.

Kielland, C., E. Skjerve, O. Østerås, and A. J. Zanella. 2010. Dairy farmer attitudes and empathy toward animals are associated with animal welfare indicators. J. Dairy Sci. 93:2998-3006.

Kristensen, E., and C. Enevoldsen. 2008. A mixed methods inquiry: How dairy farmers perceive the value(s) of their involvement in an intensive dairy herd health management program. Acta Vet. Scand. 50:50.

LeBlanc, S. J., K. D. Lissemore, D. F. Kelton, T. F. Duffield, and K. E. Leslie. 2006. Major advances in disease prevention in dairy cattle. J. Dairy Sci. 89:1267-1279.

Lievaart, J. J., and J. P. T. M. Noordhuizen. 1999. Veterinary herd health management on dairy farms in the Netherlands: Assessment by dairy farmers. Tijdschr. Diergeneeskd. 124:734-740.

Maister, D. H., C. H. Green, and R. M. Galford. 2000. The Trusted Advisor. Free Press, New York, NY.

Mohd Nor, N., W. Steeneveld, M. C. M. Mourits, and H. Hogeveen. 2012. Estimating the costs of rearing young dairy cattle in the Netherlands using a simulation model that accounts for uncertainty related to diseases. Prev. Vet. Med. 106:214-224.

Noordhuizen, J. P. T. M., and J. H. M. Metz. 2005. Quality control on dairy farms with emphasis on public health, food safety, animal health and welfare. Livest. Prod. Sci. 94:51-59.

Pennings, J. M. E., S. H. Irwin, and D. L. Good. 2002. Surveying farmers: A case study. Rev. Agric. Econ. 24:266-277.

Sorge, U., D. Kelton, K. Lissemore, A. Godkin, S. Hendrick, and S. Wells. 2010. Attitudes of Canadian dairy farmers toward a voluntary Johne's disease control program. J. Dairy Sci. 93:1491-1499.

Young, I. 2010. Attitudes towards the Canadian quality milk program and use of good production practices among Canadian dairy producers. Prev. Vet. Med. 94:43-53. 


\section{APPENDIX}

Table A1. Questions (Q) in the questionnaire, divided into questions about execution of veterinary herd health management (VHHM), openness toward information, and trust in information

\begin{tabular}{|c|c|c|c|}
\hline $\begin{array}{l}\text { Question } \\
\text { number }\end{array}$ & Part & Category & Question \\
\hline Q1 & 1 & \multirow[t]{7}{*}{ Execution of VHHM } & Do you participate in VHHM programs? (yes/no) \\
\hline Q2 & 1 & & $\begin{array}{l}\text { My veterinarian checks my animals for pregnancy (yes/no) } \\
\text { If yes, how often? (always; regularly; when problems arise; never) }\end{array}$ \\
\hline Q3 & 1 & & $\begin{array}{l}\text { My veterinarian advises me on fertility (yes/no) } \\
\text { If yes, how often? (always; regularly; when problems arise; never) }\end{array}$ \\
\hline Q4 & 1 & & $\begin{array}{l}\text { My veterinarian advises me on udder health (yes/no) } \\
\text { If yes, how often? (always; regularly; when problems arise; never) }\end{array}$ \\
\hline Q6 & 1 & & $\begin{array}{l}\text { My veterinarian advises me on nutrition (yes/no) } \\
\text { If yes, how often? (always; regularly; when problems arise; never) }\end{array}$ \\
\hline Q7 & 1 & & $\begin{array}{l}\text { My veterinarian advises me on young stock rearing (yes/no) } \\
\text { If yes, how often? (always; regularly; when problems arise; never) }\end{array}$ \\
\hline Q8 & 1 & & $\begin{array}{l}\text { My veterinarian advises me on housing (yes/no) } \\
\text { If yes, how often? (always; regularly; when problems arise; never) }\end{array}$ \\
\hline Q12 & 2 & \multirow{9}{*}{ Openness toward information } & I take part in a study club \\
\hline Q13 & 2 & & I take part in a committee/board regarding (dairy) farming \\
\hline Q14 & 2 & & I have been a testing farm for a new product/service \\
\hline Q15 & 2 & & If I were approached to be a testing farm, I would consider it \\
\hline Q16 & 2 & & How often do you visit other farms outside your region $(>50 \mathrm{~km})$ to gain knowledge? \\
\hline Q17 & 2 & & I like to be the first to use new developments \\
\hline Q18 & 2 & & I continuously try to improve farm management \\
\hline Q19 & 2 & & If I hear about interesting developments in dairy, I look it up on the internet \\
\hline Q20 & 2 & & If my veterinarian wants to talk about a new topic, I am open to that \\
\hline Q21 & 2 & \multirow[t]{5}{*}{ Trust in information } & I receive visitors on my farm \\
\hline $\mathrm{Q} 22$ & 2 & & I view other farmers as competition \\
\hline $\mathrm{Q} 23$ & 2 & & My veterinarian may see my farm data \\
\hline Q24 & 2 & & I allow others to visit my farm \\
\hline Q25 & 2 & & I grade the relationship with my veterinarian a . . (1-10) \\
\hline
\end{tabular}


Table A2. Variables that were significant in univariate logistic regression analysis with dependent variable [participation in veterinary herd health management (VHHM; yes/no)]

\begin{tabular}{|c|c|c|c|c|c|}
\hline Variable $^{1}$ & $\beta^{2}$ & $\mathrm{SE}$ & $\begin{array}{c}\text { Wald } \\
\text { statistic }\end{array}$ & $\begin{array}{c}\text { Significance } \\
(P \text {-value })\end{array}$ & Odds ratio \\
\hline Q2: I take part in a study club & 0.42 & 0.05 & 6.24 & 0.01 & 1.13 \\
\hline Q3: I take part in a committee/board regarding (dairy) farming & -0.34 & 0.16 & 4.72 & $<0.05$ & 0.71 \\
\hline Q4: I have been a testing farm for a new product/service & 0.33 & 0.16 & 4.53 & $<0.05$ & 1.39 \\
\hline Q5: If I were approached to be a testing farm, I would consider it & 0.42 & 0.14 & 8.94 & $<0.01$ & 1.53 \\
\hline Q11: I receive visitors on my farm & 0.31 & 0.14 & 5.21 & $<0.05$ & 1.36 \\
\hline Q13: My veterinarian may see my farm data & 1.31 & 0.34 & 15.13 & $<0.01$ & 3.70 \\
\hline \multicolumn{6}{|l|}{ Q15: I grade the relationship with my veterinarian a . . (1-10) } \\
\hline 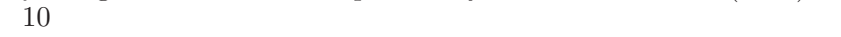 & - & - & 20.21 & $<0.01$ & - \\
\hline 3 & -1.93 & 0.84 & 5.25 & $<0.05$ & 0.15 \\
\hline 4 & -2.52 & 0.92 & 7.52 & $<0.01$ & 0.08 \\
\hline 5 & -1.89 & 0.58 & 10.53 & $<0.01$ & 0.15 \\
\hline 6 & -1.45 & 0.48 & 9.09 & $<0.01$ & 0.24 \\
\hline 7 & -0.85 & 0.44 & 3.78 & 0.05 & 0.43 \\
\hline 8 & -0.41 & 0.44 & 0.91 & 0.34 & 0.66 \\
\hline 9 & 0.08 & 0.48 & 0.03 & 0.86 & 1.09 \\
\hline \multicolumn{6}{|l|}{ Q16: I follow the advice of my feed advisor } \\
\hline Agree & - & - & 9.84 & $<0.01$ & - \\
\hline Neutral & -0.47 & 0.16 & 8.28 & $<0.01$ & 0.63 \\
\hline Disagree & -0.76 & 0.52 & 2.12 & 0.15 & 0.47 \\
\hline \multicolumn{6}{|l|}{ Q17: I follow the advice of my veterinarian } \\
\hline Agree & - & - & 39.47 & $<0.05$ & - \\
\hline Neutral & -1.08 & 0.18 & 36.39 & $<0.01$ & 0.34 \\
\hline Disagree & -1.12 & 0.52 & 4.58 & $<0.05$ & 0.33 \\
\hline \multicolumn{6}{|l|}{ Q7: I like to be the first to use new developments } \\
\hline Agree & - & - & 6.83 & $<0.05$ & - \\
\hline Neutral & -0.31 & 0.18 & 2.87 & 0.09 & 0.73 \\
\hline Disagree & -0.53 & 0.20 & 6.83 & $<0.01$ & 0.59 \\
\hline \multicolumn{6}{|l|}{ Q8: I continuously try to improve farm management } \\
\hline Agree & - & - & 14.62 & $<0.01$ & - \\
\hline Neutral & -0.57 & 0.16 & 13.22 & $<0.01$ & 0.57 \\
\hline Disagree & -0.50 & 0.29 & 2.95 & 0.08 & 0.61 \\
\hline \multicolumn{6}{|l|}{ Q10: If my veterinarian wants to talk about a new topic, I listen } \\
\hline Agree & - & - & 19.37 & $<0.01$ & - \\
\hline Neutral & -0.47 & 0.49 & 0.91 & 0.34 & 0.63 \\
\hline Disagree & -0.79 & 0.18 & 18.92 & $<0.01$ & 0.46 \\
\hline \multicolumn{6}{|l|}{ Q18: External advice does not add to my own knowledge } \\
\hline Agree & - & - & 3.99 & 0.14 & - \\
\hline Neutral & 0.11 & 0.15 & 0.56 & 0.45 & 1.21 \\
\hline Disagree & -0.32 & 0.20 & 2.49 & 0.11 & 0.73 \\
\hline \multicolumn{6}{|c|}{ Q19: The most important reason not to use external advisors is a financial reason } \\
\hline Agree & - & - & 5.14 & 0.76 & - \\
\hline Neutral & -0.10 & 0.17 & 0.39 & 0.53 & 0.90 \\
\hline Disagree & -0.36 & 0.16 & 5.03 & 0.03 & 0.70 \\
\hline \multicolumn{6}{|l|}{ Q20: I do not like to share my farm data with other farmers } \\
\hline Agree & - & - & 4.74 & 0.94 & - \\
\hline Neutral & -0.08 & 0.22 & 0.13 & 0.72 & 0.92 \\
\hline Disagree & 0.24 & 0.20 & 1.48 & 0.22 & 1.27 \\
\hline
\end{tabular}

${ }^{1} \mathrm{Q}=$ question.

${ }^{2}$ The regression coefficient, representing the relative importance of a predictor in predicting the criterion. 
Table A3. Variables that were significant in univariate logistic regression analysis with dependent variable [number of topics discussed during veterinary herd health management (VHHM); 1-9]

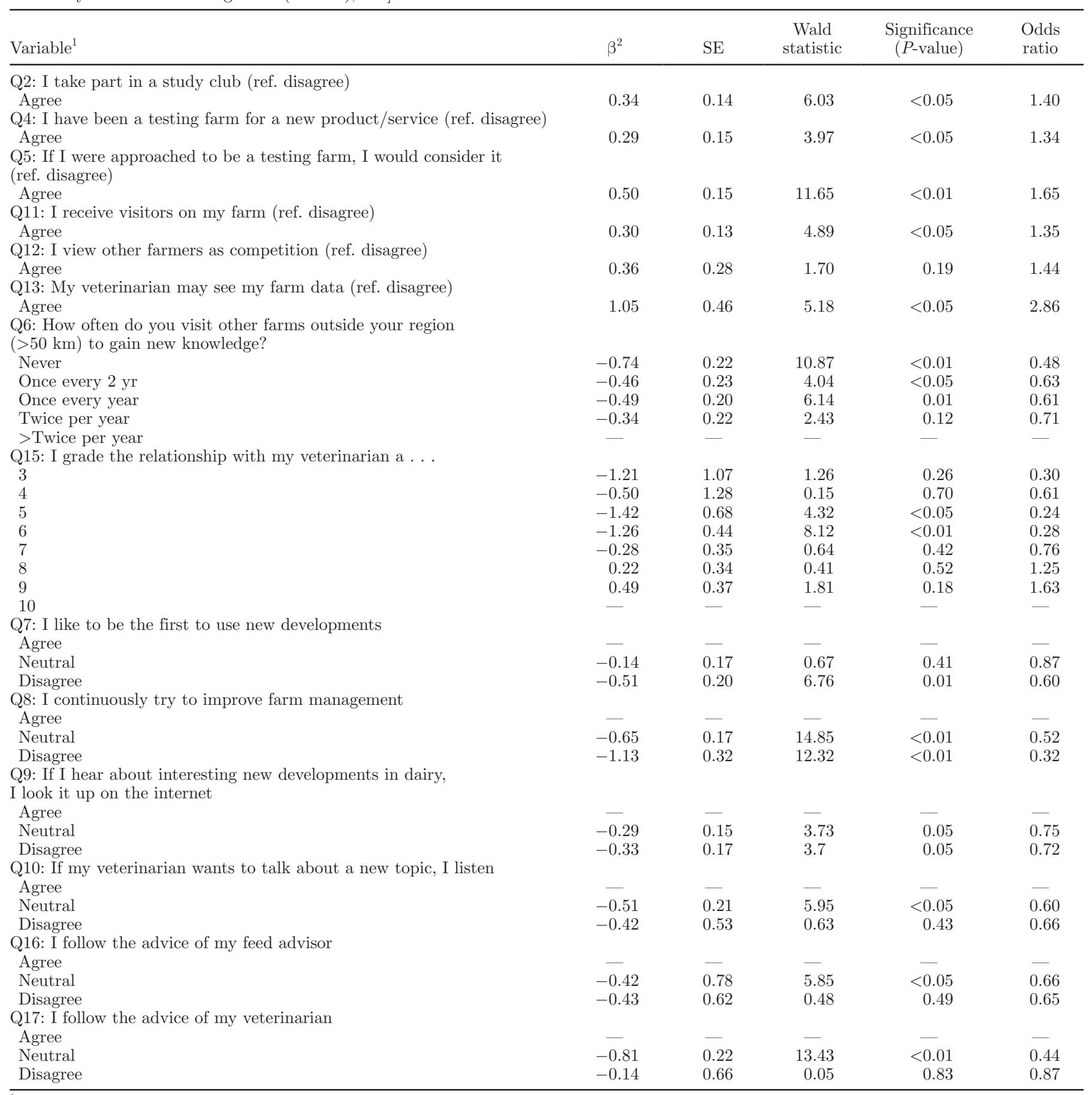

${ }^{1} \mathrm{Q}=$ question; ref. $=$ reference.

${ }^{2}$ The regression coefficient, representing the relative importance of a predictor in predicting the criterion. 
Table A4. Factor loadings (distance to factor) of the 20 questions (Q) regarding farmers' attitudes toward information in factor analysis after varimax rotation, eigenvalue, percentage variance, and Cronbach's $\alpha$ per factor ${ }^{1}$

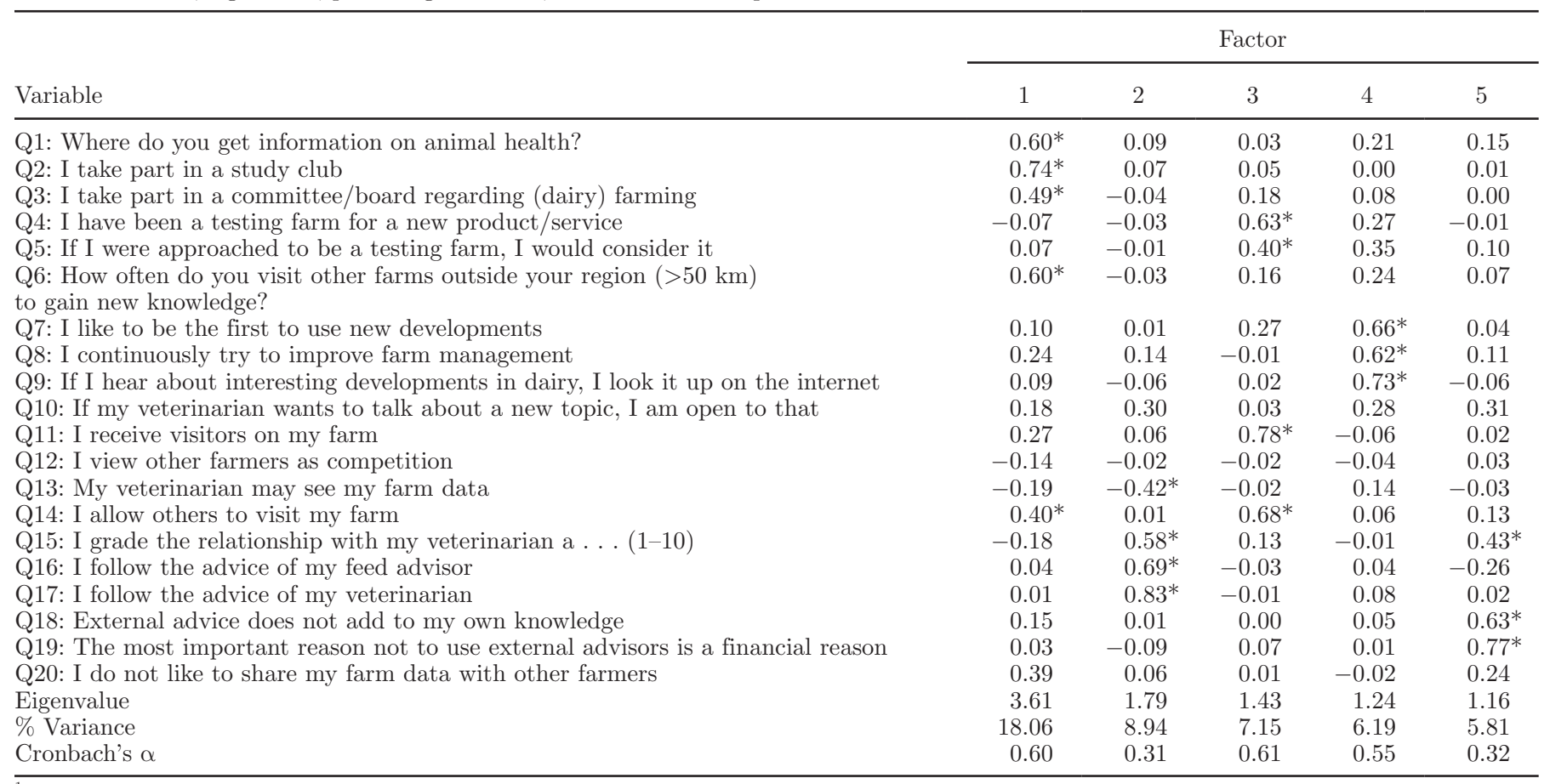

${ }^{1}$ Information for goodness-of-fit: Kaiser-Meyer-Olkin test for sampling adequacy: 0.76; Bartlett's test for sphericity: $<0.01$.

*The cutoff value for the factor loadings was set at $>0.40$ and, thus, close to the underlying construct (factor). 
Table A5. Variables that were significant in univariate logistic regression analysis with dependent variable [participation in veterinary herd health management (VHHM); yes/no)] and independent variables (the 20 questions regarding the use of information and forced entry of number of cows $\times$ veterinary practice size)

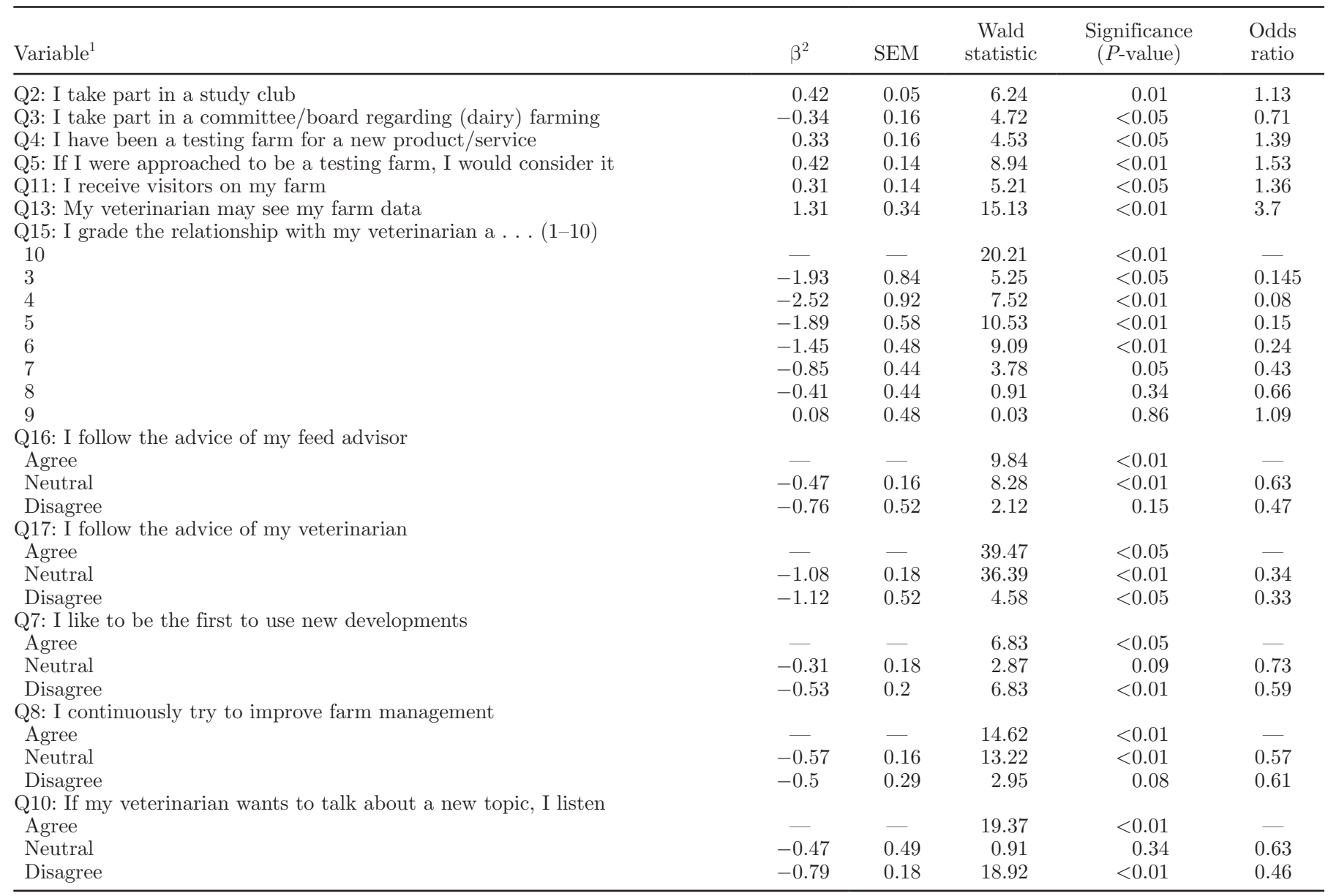

${ }^{1} \mathrm{Q}=$ question.

${ }^{2}$ The regression coefficient, representing the relative importance of a predictor in predicting the criterion. 